\title{
Article
}

\section{The Relationship between Alcohol Hangover Severity, Sleep and Cognitive Performance; a Naturalistic Study}

\author{
Elizabeth Ayre ${ }^{1}$, Andrew Scholey ${ }^{1,2}\left(\mathbb{D}\right.$, David White ${ }^{1,3} \mathbb{0}$, Grant J. Devilly ${ }^{4,5}$, Jordy Kaufman ${ }^{6}$, \\ Joris C. Verster ${ }^{1,7} \mathbb{C}^{-}$, Corey Allen ${ }^{8}$ and Sarah Benson $1, * \mathbb{C}$ \\ 1 Centre for Human Psychopharmacology, Swinburne University, Melbourne, VIC 3122, Australia; \\ eayre@swin.edu.au (E.A.); andrew@scholeylab.com (A.S.); dawhite@swin.edu.au (D.W.); \\ j.c.verster@uu.nl (J.C.V.) \\ 2 Nutrition Dietetics and Food, School of Clinical Sciences, Monash University, Melbourne, VIC 3800, Australia \\ 3 Swinburne Neuroimaging, Swinburne University, Melbourne, VIC 3122, Australia \\ 4 School of Applied Psychology, Griffith University, Brisbane, QLD 4122, Australia; grant@devilly.org \\ Griffith Criminology Institute, Griffith University, Brisbane, QLD 4122, Australia \\ 6 Swinburne BabyLab, Swinburne University, Melbourne, VIC 3122, Australia; jkaufman@swin.edu.au \\ 7 Division of Pharmacology, Utrecht University, 3584 CG Utrecht, The Netherlands \\ 8 Queensland Police Service Academy, Brisbane, QLD 4108, Australia; allencorey1966@hotmail.com \\ * Correspondence: sarahbenson@swin.edu.au
}

check for updates

Citation: Ayre, E.; Scholey, A.; White, D.; Devilly, G.J.; Kaufman, J.; Verster, J.C.; Allen, C.; Benson, S. The Relationship between Alcohol Hangover Severity, Sleep and Cognitive Performance; a Naturalistic Study. J. Clin. Med. 2021, 10, 5691. https://doi.org/10.3390/jcm10235691

Academic Editors: Antonio Preti and Michele Roccella

Received: 20 September 2021 Accepted: 29 November 2021 Published: 3 December 2021

Publisher's Note: MDPI stays neutral with regard to jurisdictional claims in published maps and institutional affiliations.

Copyright: (c) 2021 by the authors. Licensee MDPI, Basel, Switzerland. This article is an open access article distributed under the terms and conditions of the Creative Commons Attribution (CC BY) license (https:// creativecommons.org/licenses/by/ $4.0 /)$.

\begin{abstract}
Alcohol hangover ( $\mathrm{AH}$ ) has been associated with poor sleep due to the negative effects of alcohol intoxication on sleep quantity and sleep quality. The aim of the current study was to further explore the relationship between $\mathrm{AH}$ severity and sleep using a naturalistic study design. A further aim was to determine whether quantitative aspects of sleep were a mediating influence on the relationship between $\mathrm{AH}$ severity and cognitive performance. As part of the naturalistic study design, 99 drinkers were recruited following a night of drinking in an Australian state capital, with breath alcohol concentration $(\mathrm{BrAC})$ measured as participants were leaving the entertainment district. The following morning at home, participants answered online questions regarding their drinking behaviour on the previous evening, current AH symptoms and sleep quality. Participants also completed an online version of the Trail-Making Test B (TMT-B) to assess cognitive performance. The findings reveal the duration of nightly awakenings to be negatively related to six individual $\mathrm{AH}$ symptoms as well as overall AH severity. The number of nightly awakenings, sleep quality and total sleep time correlated with four $\mathrm{AH}$ symptoms including overall $\mathrm{AH}$ severity. Total $\mathrm{AH}$ severity accounted for a moderate amount of variance $(11 \%)$ in the time to complete the TMT-B. These findings confirm that alcohol consumption negatively affects sleep, which is related to higher next-day hangover severity ratings and poorer cognitive performance.
\end{abstract}

Keywords: alcohol hangover; sleep quantity; sleep quality; executive functioning; working memory; attention

\section{Introduction}

Alcohol hangover $(\mathrm{AH})$ is described as an array of negative physical and mental symptoms that develop after a single episode of heavy alcohol consumption when the blood alcohol concentration (BAC) is nearing 0.00\% [1,2]. AH typically follows alcohol consumed to an equivalent $\mathrm{BAC}$ of $\geq 0.11 \%$, although recent research indicates that it can also occur after relatively low doses [3,4]. Common AH symptoms include headache, thirst and nausea, as well as sleep-related complaints such as fatigue and drowsiness which are often rated as the most severe [5-7]. Several studies have also found AH-induced impairments in cognitive functions including attention, memory, psychomotor speed and executive functioning [8-13]. Impaired cognitive functioning may be a factor in AH-related workplace absenteeism and reduced productivity, which costs the UK an estimated GBP 1.4 billion [14] and the US over USD 249 billion annually [15]. 
Many physiological mechanisms contribute to the presence of AH symptoms. These include, but are not limited to, dehydration, hormonal imbalances, oxidative stress and inflammation [16-18]. Biological factors such as age, as well as beverage congeners, which are toxic substances in alcoholic beverages other than ethanol (e.g., methanol), can also contribute to the severity of AH symptoms $[10,19,20]$. Another potential contributor to $\mathrm{AH}$ severity is the effects of alcohol intoxication on sleep architecture. Consuming alcohol prior to bed can have a negative influence on sleep by altering biological sleep rhythms [21,22]. Specifically, at high concentrations, alcohol has sedative properties and is often still being metabolised at sleep onset $[10,21]$. The body adjusts to this by reducing sleep onset latency, that is, the time it takes to fall asleep, as well as delaying rapid eye movement (REM) sleep and increasing the time spent in deep slow-wave sleep $[10,21,23]$. However, in the second half of sleep when blood alcohol concentrations decline, compensatory changes known as "rebound effects" occur [21]. This consequently increases REM and wake periods (i.e., the number and/or duration of awakenings after sleep onset), ultimately reducing sleep quantity and quality.

Despite this understanding, relatively few studies have explored the relationship between AH and sleep. Some existing research comes from studies using an experimental research design. Experimental designs involve inducing an AH state in a laboratory setting and controlling alcohol administration, as well as food and water intake and the time allocated to sleep [24]. One experimental study used polysomnography to monitor sleep following alcohol administered to a breath alcohol concentration (BrAC) of $0.11 \%$ [10]. Findings revealed an increase in wake periods (duration of awakenings) and a decrease in sleep efficiency (i.e., the proportion of time in bed that was actually spent sleeping), characteristic of high-dose consumption. Poorer self-reported sleep quality was also found, but there was no difference in total sleep time (TST). In contrast, another experimental study found no difference in sleep quality following alcohol administered to a peak mean $\mathrm{BrAC}$ of $0.155 \%$ [12]. A third study where alcohol was administered to a mean BrAC of $0.115 \%$ found no reduction in TST, but even improved sleep quality following alcohol compared with placebo [25]. Common to these conflicting studies was a short alcohol administration period ( $30 \mathrm{~min}-1.5 \mathrm{~h}$ ) and $7-8 \mathrm{~h}$ of allocated sleep. Other limitations of experimental studies include ethical restrictions on the dose (generally capped at $1 \mathrm{~g}$ of alcohol per kilo body weight) and type of alcohol administered, which may also contribute to mixed outcomes $[8,24]$.

Other AH studies have used semi-naturalistic research designs to study the association between $\mathrm{AH}$ and sleep. Unlike experimental designs, semi-naturalistic designs allow participants to self-initiate drinking in a familiar environment and attend a laboratory for testing the following morning when experiencing $\mathrm{AH}$ (for a further review, see Verster et al. [24]). Semi-naturalistic designs have high ecological validity and demonstrate that drinking frequently occurs at the expense of sleep, intensifying AH severity [24,26,27]. Verster et al. [7] found that after alcohol, time to bed was delayed by an average of $2 \mathrm{~h}$, TST decreased by $1.5 \mathrm{~h}$ and the reduced TST negatively correlated with "being tired". Self-reported sleep quality was also poorer after alcohol, a finding consistent with other semi-naturalistic studies [26,28], some of which additionally found reduced sleep onset latency $[29,30]$ and increased awakenings (number of awakenings) after sleep onset [4]. However, in one study, TST did not decrease following alcohol when this was assessed via the levels of movement recorded on an accelerometer (wearable technology), as well as self-report measures [28].

While most of these studies have reported at least some association between $\mathrm{AH}$ and poor sleep, research design and other methodological differences such as the sleep variables assessed have resulted in inconsistencies [8,31]. This indicates research is needed to further elucidate this relationship. This could be approached in two ways. Firstly, an alternative naturalistic research design could be used. In a naturalistic design, participants are recruited when already out drinking, with on-field collected $\mathrm{BrAC}$ readings [32]. AH and sleep are then conveniently assessed at home using online measures. This research design has several 
advantages including the ability to obtain BrAC readings without influencing any prior drinking behaviours. In addition, sleep characteristics are not disrupted by the requirement to attend a testing site at a specified time, which is a common factor of both experimental and semi-naturalistic designs. This could provide more insight into normal sleep patterns following alcohol.

The second approach to further understand $\mathrm{AH}$ and sleep is to examine the severity of specific AH symptoms and compare these with the variety of sleep variables assessed in previous research. This includes the number and duration of nightly awakenings that have only been considered in two of the studies mentioned previously $[4,10]$. Two recent survey studies somewhat conducted this by comparing individual $\mathrm{AH}$ symptoms and select sleep measures $[33,34]$. In one study, headache, weakness, dizziness, hot/cold flushes and stomach pain correlated with TST [33]. The second study reported similar correlations using sleep quality and daytime sleepiness [34]. However, in both studies, limited sleep characteristics were assessed and $\mathrm{AH}$ was only measured retrospectively, which may partially explain the mostly weak correlations (i.e., $r<0.2$ ).

A third factor that very few studies have examined is whether sleep is a compounding influence on the relationship between AH severity and cognitive performance [10]. Previous studies assessing the within-subject effects of AH have noted impairments in selective and sustained attention [13,35], psychomotor speed [11,36,37] and memory recall $[36,38,39]$. Rohsenow et al. [10] also found that AH severity positively correlated with reaction times on two tasks of sustained attention (i.e., the psychomotor vigilance task, and a continuous performance test). However, although higher AH severity also resulted in a lower sleep efficiency and REM percentage, these measures did not mediate the relationship between AH severity and task performance. This is somewhat unusual considering disrupted sleep has been observed to negatively impact cognitive performance across similar domains to AH. A meta-analysis on the cognitive effects of sleep deprivation indicated that the speed and accuracy of performance on simple and complex attention, working memory and information processing were all impaired following short-term sleep disruption ( $<48 \mathrm{~h})$ [40]. In some cases, partial sleep loss $(<5 \mathrm{~h}$ sleep) has shown to be more detrimental to cognitive functioning than short-term $(<48 \mathrm{~h})$ or long-term $(>48 \mathrm{~h})$ sleep deprivation [41].

The Trail-Making Test B (TMT-B) is a validated and reliable measure of cognitive flexibility, attention and working memory [42,43]. Previous research has shown the TMT-B to be sensitive in determining impairments relating to sleep loss [44-46] as well as the effects of acute alcohol [47-49]. Recent AH studies exploring higher-order functions including cognitive flexibility [39], working memory updating [9,50] and reward learning [51] have also reported impairments in the speed and/or accuracy of performance during $\mathrm{AH}$ compared to non-AH conditions. Therefore, it is worth considering whether these impairments are also related to the severity of $\mathrm{AH}$ and whether this is exacerbated by poor sleep.

The aim of the current study was to adopt a naturalistic study design to further explore the relationship between $\mathrm{AH}$ symptom severity and quantitative and qualitative aspects of sleep using multiple sleep characteristics. Based on previous research, the variables of interest in relation to sleep include the time to bed, time to fall asleep (i.e., sleep onset latency), the number and duration of awakenings after sleep onset, the total sleep time and sleep quality. A further aim was to determine whether sleep characteristics found to be strongly related to $\mathrm{AH}$ act as a mediating influence over the relationship between $\mathrm{AH}$ severity and performance on the TMT-B.

\section{Materials and Methods}

\subsection{Design}

This study formed part of a larger series of projects aimed at investigating the drinking patterns and motivations for drinking in an Australian sample [52,53]. The larger 'Last Drinks' study $[53,54]$ included breathalysing and collecting data pertaining to alcohol consumption from 2516 individuals over several months. The current study involved a 
subset of the larger cohort $(n=346)$. Data for this study was collected during one month of the larger study. This study was a naturalistic design whereby participants were recruited after an evening of drinking as they were leaving entertainment districts of an Australian state capital (Brisbane) and were then contacted the following morning to complete online measures. This study was approved by Griffith University (2015/704) and Swinburne University Human Research Ethics Committees (SUHREC, 2016/167).

\subsection{Participants}

Participants were recruited at exit points around the central night-time entertainment districts of Brisbane. To be eligible, participants were required to be on their way home after an evening of drinking, be 18 years of age or over and proficient in the English language. Participants were also required to have a mobile phone and access to a desktop, laptop or tablet computer to complete next-day assessments.

\subsection{Measures}

\subsubsection{Breath Alcohol Content (BrAC)}

Alcohol content was measured via expired breath using an Alcolizer LE5 (Alcolizer Pty Ltd., Perth, Australia). This device was calibrated by Queensland police, is Australian standard 3547 certified and has an accuracy of $>0.005$ at $0.100 \mathrm{BrAC}$ g/100 mL [34]. Field research measuring intoxication levels in people attending night-time entertainment districts found this device to be reliable and valid [55].

\subsubsection{Alcohol Consumption}

Participants were asked to state the number of standard drinks (i.e., 1 unit $=10 \mathrm{~g}$ pure alcohol in Australia) consumed the previous evening and hours spent drinking [56]. Drink options included beer/cider, wine, spirits (alone), spirits with mixed beverages and alcohol mixed with energy drinks. Information on the specific spirits consumed to ascertain the level of beverage congeners consumed was not collected.

\subsubsection{Alcohol Hangover Severity Scale (AHSS)}

The AHSS assesses the severity of AH symptoms on an 11-point Likert-type scale ranging from 1 (absent) to 11 (extreme) [57]. Individual scores are added and averaged to indicate total AH severity. An 11-item version of the scale was used with the original item "concentration problems" being omitted. This was to reduce expectancy effects associated with engaging in a task requiring focussed attention [32]. The AHSS has been found to have good reliability and validity (Cronbach's $\alpha=0.85$ ) [57].

\subsubsection{Core Consensus Sleep Diary (CSD)}

The CSD is a self-report measure used for summarising quantitative and qualitative aspects of sleep [58]. The CSD was composed of 7 items relating to sleep quantity and a single eighth item relating to sleep quality. For sleep quantity, participants responded to questions such as "what time did you go to bed" and "what was the time of your final wake up" in $12 \mathrm{~h}$ time to the nearest 5 min interval (e.g., 8:00 a.m., 8:05 a.m., 8:10 a.m.). Sleep quantity items were "time to bed", "sleep onset latency", "number of awakenings", "duration or nightly awakenings" and "time of final waking". Responses to these 5 items were also calculated to determine the total sleep time and total time in bed, creating seven sleep quantity scores.

For the single item for sleep quality, participants were asked to indicate "how would you rate the quality of your sleep last night" on a 5-point Likert-type scale ranging from 1 (very poor) to 5 (very good). In addition, to assess whether sleep quality differed from a normal night's sleep, participants were also asked to rate their sleep quality for a normal night's sleep (i.e., "on nights when you have not been drinking alcohol, how would you rate the general quality of your sleep"), which was measured on the same 5-point scale. 


\subsubsection{Online Trail-Making Task (TMT-B)}

The TMT-B assesses cognitive flexibility, attentional set shifting and working memory [43]. The task includes letters (A-L) and numbers (1-13) presented in boxes in a random $5 \times 5$ grid pattern. Participants had to click on the boxes in an alternating digit/letter pattern (i.e., 1-A-2-B-3-C) as quickly and accurately as possible. A red flash in the box indicated an incorrect response. Outcome measures were completion time in seconds and total errors. Previous research found a high correspondence between the traditional pencil-and-paper and the online version [32].

\subsection{Procedure}

Researchers were stationed at major public transport hubs including taxi ranks and train stations in two locations across Brisbane, Australia. As part of the larger research project, participants were randomly approached on their way out of the bar districts between $12 \mathrm{a} . \mathrm{m}$. and $5 \mathrm{a}$ a.m. and were presented with a verbal summary of the nature of the whole project and the specific study requirements. Every fourth person was initially asked to participate, and, after a refusal, every next person (or group) was approached (see Devilly, et al. [53]. Informed consent was obtained by the participants' verbal agreement to be interviewed and to participate in night-time breathalyser measure assessments (as approved by both ethics committees). Participants willing to be interviewed were given a unique identifier card that had a link to the study information sheet (www.last-drinks.com) if they wished to obtain further information or to anonymously withdraw their data. Next, participants provided demographic information (i.e., age and gender) and completed a survey on their consumption that evening (results reported in Devilly et al. [53]). A BrAC reading was then taken, and participants were not restricted from knowing their result. Any participant with a $\mathrm{BrAC}$ reading $\geq 0.05 \%$ was invited to participate in the current study and complete online measures the following morning. The risk of bias from expectancy effects the following morning was thought to be minimal as previous research found no difference in cognitive performance during $\mathrm{AH}$ when participants were aware or not of the study purpose [59].

Consenting participants provided their mobile contact details and an estimated bedtime. Participants were contacted $8 \mathrm{~h}$ after their estimated bedtime via personal text message as a reminder to complete the online measures (i.e., $8 \mathrm{~h}$ represents an average night's sleep and was the allowance used in previous experimental studies $[10,25])$. The text message contained a unique identifying number and directions to the secure website. Participants completed the online measures in a private residence in the following order: resupply of demographic information and alcohol consumption, AHSS, CSD and TMT-B. Alcohol consumption was recollected to account for any further alcohol that may have been consumed after leaving the entertainment districts. Total participation time did not exceed $15 \mathrm{~min}$. At completion, participants were directed to another website to be compensated with an AUD 15 voucher.

\subsection{Analysis}

Data were analysed using SPSS version 27 (IBM Corp, Armonk, NY, USA). Initial screening revealed eight cases missing $>30 \%$ of their total data. These cases were removed. A further nine participants had missing or spurious data on a single sleep variable. In order to calculate total sleep time and total time in bed, individual missing data points were replaced using a surrogate variable (e.g., "time out of bed" was used to replace "time of final wake up" and vice versa) [60]. One significant multivariate outlier was detected and removed. Initial inspections of histograms and P-P plots indicated most variables were skewed with the exception of total AH severity and select sleep variables (i.e., time of final wake up, total sleep time and total time in bed) which assumed normality. To correct for skewness in TMT-B completion times (s), log transformations were applied to the data and all subsequent analyses were run using both corrected and uncorrected scores. In other cases, transformations were unable to correct for violations of normality due to a high 
proportion of scores being close to or equalling zero (e.g., sleep onset latency, the number of nightly awakenings, duration of nightly awakenings and TMT-B errors) or a high number of extreme scores (e.g., 12\% of scores for "fatigue" were rated as extremely high). However, examination of scatterplots indicated that all $\mathrm{AH}$, sleep and performance variables formed reasonably monotonic relationships with all other $\mathrm{AH}$, sleep and performance variables. Therefore, non-parametric statistics were employed.

Data analysis occurred in two phases. In the first phase, to confirm whether sleep quality was poorer after a night of drinking, the single item for sleep quality from the CSD was compared with the similar item measuring a normal night's sleep using a two-tailed paired samples $t$-test. To account for any issues with non-normality, non-parametric Wilcoxon signed-rank tests were employed to confirm or reject the null. Next, the relationships between AH symptoms, sleep characteristics and TMT-B performance were analysed using two methods. Variables that assumed normality (i.e., total AH severity, time of final wake up, total sleep time, total time in bed and TMT-B completion times, which was corrected to normal) were compared using Pearson's correlations. All other variables were assessed using non-parametric Spearman's rank correlations. In the second phase, as determined through the results of Pearson's correlations only (due to any potential issues with nonlinear relationships), sleep variables that had formed a relationship with both AH severity and TMT-B performance (that is, only total sleep time) were subject to a Preacher and Hayes mediation analysis [61]. As age is also considered a possible influence on AH and sleep, the mediation analysis was also run with age as a potential covariate.

\section{Results}

\subsection{Participant Characteristics}

Of the 346 participants who consented to the current study, 108 completed next-day measures (31\% participation rate) of which 99 provided usable data sets. As outlined in Scholey, et al. [32], there was no difference in the level of intoxication between those who did and did not participate in next-day measures.

Participants were $52 \%$ male and had a mean age of 24.16 ( \pm 5.68 ; range $18-49)$ years. On the evening of drinking, participants consumed an average of $13.85( \pm 6.38)$ drinks over $7.55( \pm 3) h$, resulting in a mean BrAC of $0.111 \%( \pm 0.04)$ at the time of leaving the entertainment districts. Table 1 displays the means and standard deviations for $\mathrm{AH}$ symptoms, sleep characteristics and TMT-B performance. To ease interpretation, uncorrected scores for TMT-B (s) are presented. As shown in Table 1, participants went to bed after 3 a.m. on average, with the TST just less than $5 \mathrm{~h}$. For AH symptoms, "fatigue" had the highest mean severity, followed by "thirst". All other symptoms including total AH severity were rated as mild $(<3)$ to moderate (3-6) in severity.

\subsection{Sleep Quality}

To confirm whether sleep quality following an evening of drinking differed from a normal night's sleep, the single sleep quality item from the CSD (i.e., "how would you rate the quality of your sleep") was compared with the similar single sleep quality item measuring a normal night's sleep. Sleep quality after an evening of drinking was found to be significantly poorer, $t(98)=2.90, p=<0.01, d=0.4$, CI $[0.13,0.7]$, with a moderate effect size.

\subsection{Correlations}

Table 2 presents the correlations for drinking characteristics, AH symptoms, sleep and task performance. 
Table 1. Means and standard deviations for $\mathrm{AH}$ and sleep characteristics.

\begin{tabular}{lcc}
\hline \multicolumn{1}{c}{ Variable } & Mean & SD \\
\hline Sleep Characteristics & & \\
Time to bed (h:m) & $3: 41$ & $1: 07$ \\
Sleep onset latency (h:m) & $0: 32$ & $0: 47$ \\
No. nightly awakenings & 1.32 & 1.84 \\
Duration of nightly & $0: 07$ & $0: 16$ \\
awakenings (min) & $9: 29$ & $1: 48$ \\
Time of final wake up (h:m) & $4: 58$ & $2: 06$ \\
Total sleep time (h:m) & $6: 32$ & $1: 50$ \\
Total time in bed (h:m) & 3.31 & 1.15 \\
Sleep quality & 3.73 & 0.9 \\
Normal sleep quality & & \\
AH Symptoms & 3.85 & 1.42 \\
Total AH severity & 7.55 & 2.49 \\
Fatigue & 4.57 & 2.88 \\
Apathy & 3.86 & 2.51 \\
Clumsiness & 2.76 & 2.19 \\
Confusion & 7.15 & 2.47 \\
Thirst & 3.08 & 2.53 \\
Sweating & 1.25 & 1.05 \\
Shivering & 2.72 & 2.56 \\
Stomach pain & 3.87 & 2.78 \\
Nausea & 3 & 2.27 \\
Dizziness & 2.55 & 2.36 \\
Heart pounding & & \\
Cognitive & 55.29 & 2.19 \\
Performance-TMT-B & 2.57 & \\
Completion time (s) & & \\
Number of errors & & \\
\hline
\end{tabular}

\subsubsection{Drinking Characteristics}

As shown in Table 2, hours drinking and the total drinks consumed correlated with the time to bed as well as completion times on the TMT-B. Hours drinking also correlated with total sleep time and the total time in bed. BrAC did not correlate with any sleep or performance variables (for correlations between drinking characteristics and $\mathrm{AH}$ severity, see Scholey et al. [32]).

\subsubsection{AH Severity and Sleep Characteristics}

As shown in Table 2, total AH severity was related to the most sleep characteristics, positively correlating with the number and duration of nightly awakenings and negatively correlating with total sleep time and sleep quality. The single sleep characteristic that correlated with the most other $\mathrm{AH}$ variables was the duration of nightly awakenings, which correlated with six individual AH symptoms. The number of nightly awakenings, total sleep time and sleep quality also correlated with three individual AH symptoms, of which the latter two formed moderate negative correlations with the single item "fatigue". The time of final wake up and total time in bed only correlated with one individual AH item, while the time to bed and sleep onset latency did not correlate with any AH symptoms.

\subsubsection{AH Severity, Sleep and TMT-B Performance}

Times to complete the TMT-B (s) positively correlated with total AH severity as well as seven other individual AH symptoms. TMT-B completion times also negatively correlated most with total sleep time as well as total time in bed, and positively correlated with time to bed. The single item "fatigue", time of final wake up and total time in bed were the only variables related to the number of errors on the TMT-B. 
Table 2. Correlation coefficients for sleep characteristics, drinking characteristics, AH symptoms and cognitive performance.

\begin{tabular}{|c|c|c|c|c|c|c|c|c|c|c|}
\hline \multirow[b]{2}{*}{ Variables } & \multicolumn{8}{|c|}{ Sleep Characteristics } & \multicolumn{2}{|c|}{ Cognitive Performance } \\
\hline & Time to Bed & $\begin{array}{l}\text { Sleep Onset } \\
\text { Latency }\end{array}$ & $\begin{array}{l}\mathbf{N}^{\circ} \text {. Nightly } \\
\text { Awakenings }\end{array}$ & $\begin{array}{c}\text { Duration of } \\
\text { Nightly } \\
\text { Awakenings }\end{array}$ & $\begin{array}{l}\text { Time of Final } \\
\text { Wake Up }\end{array}$ & $\begin{array}{l}\text { Total Sleep } \\
\text { Time }\end{array}$ & $\begin{array}{c}\text { Total Time in } \\
\text { Bed }\end{array}$ & Sleep Quality & TMT-B (s) & $\underset{\text { (Err) }}{\text { TMT-B }}$ \\
\hline \multicolumn{11}{|l|}{ Drinking Characteristics } \\
\hline BrAC & 0.160 & -0.169 & -0.010 & -0.035 & 0.096 & 0.041 & -0.152 & 0.040 & 0.186 & -0.028 \\
\hline Hours drinking & $0.341^{* *}$ & -0.039 & 0.197 & 0.182 & -0.033 & $-0.238^{*}$ & $-0.258^{* *}$ & -0.164 & $0.294^{* *}$ & 0.108 \\
\hline Total drinks & $0.235^{*}$ & 0.037 & -0.018 & -0.033 & 0.073 & -0.076 & -0.165 & 0.025 & $0.212 *$ & 0.102 \\
\hline \multicolumn{11}{|l|}{ AH Symptoms } \\
\hline Total AH severity & 0.174 & 0.024 & $0.252 *$ & $0.302 *$ & 0.032 & $-0.229^{a}$ & -0.112 & $-0.236^{*}$ & $0.286^{b}$ & 0.114 \\
\hline Fatigue & 0.180 & 0.085 & 0.153 & 0.188 & -0.164 & $-0.320 * *$ & $-0.241 *$ & $-0.309 * *$ & $0.289^{* *}$ & $0.219 *$ \\
\hline Clumsiness & 0.066 & 0.099 & 0.162 & $0.216^{*}$ & 0.058 & -0.193 & -0.028 & -0.153 & $0.199 *$ & -0.003 \\
\hline Confusion & 0.178 & 0.028 & 0.117 & 0.162 & 0.027 & -0.126 & -0.167 & $-0.203 *$ & $0.253^{*}$ & 0.101 \\
\hline Thirst & -0.011 & 0.055 & 0.132 & $0.204 *$ & -0.171 & $-0.243^{*}$ & -0.165 & -0.169 & 0.253 * & 0.052 \\
\hline Sweating & 0.119 & 0.030 & 0.251 * & $0.218 *$ & -0.044 & -0.116 & -0.133 & -0.182 & 0.161 & 0.102 \\
\hline Shivering & 0.053 & -0.075 & $0.341 *$ & $0.280 * *$ & 0.014 & -0.158 & -0.021 & -0.193 & 0.087 & 0.010 \\
\hline Stomach pain & 0.196 & 0.059 & 0.163 & 0.138 & -0.018 & -0.263 * & -0.177 & -0.184 & $0.203 *$ & 0.138 \\
\hline Nausea & 0.090 & -0.028 & 0.145 & $0.202 *$ & 0.024 & -0.048 & -0.037 & -0.060 & 0.234 * & 0.052 \\
\hline Dizziness & -0.053 & -0.031 & 0.140 & 0.141 & 0.003 & -0.080 & 0.099 & -0.039 & 0.125 & -0.019 \\
\hline Heart pounding & 0.163 & -0.018 & $0.308^{* *}$ & $0.276^{* *}$ & 0.041 & -0.101 & -0.031 & $-0.241 *$ & $0.292 * *$ & 0.137 \\
\hline \multicolumn{11}{|l|}{ Cognitive Performance } \\
\hline TMT-B (s) & $0.214^{*}$ & -0.013 & 0.118 & 0.191 & -0.188 & $-0.235^{\mathrm{a}}$ & $-0.207^{*}$ & -0.130 & - & - \\
\hline TMT-B (Érr) & 0.148 & -0.032 & -0.080 & -0.041 & $-0.201^{*}$ & -0.145 & $-0.210 *$ & -0.005 & - & - \\
\hline
\end{tabular}

Note: Significant differences in Spearman's rank correlations $\left(r_{s}\right)$ denoted as ${ }^{*} p<0.05$, and ${ }^{* *} p<0.001$; significant differences in Pearson's correlations $(r)$ denoted as ${ }^{\text {a }} p<0.05$, and ${ }^{\mathrm{b}} p<0.001$. 


\subsection{Mediation}

Although "fatigue", "thirst" and "stomach pain" correlated with both TMT-B (s) and TST, these correlations were conducted using non-parametric statistics and as such were not appropriate for any further mediation analysis. Given that TST was the only sleep variable that correlated with both total AH severity and TMT-B (s), a mediation analysis was conducted with TST as the mediating variable between total AH severity and TMT-B (s). Analysis of log-transformed and uncorrected scores on the TMT-B (s) revealed similar outcomes, so for ease of interpretation, the untransformed scores are presented. As shown in Figure 1, the findings reveal a significant overall model for predicting completion times on the TMT-B from AH severity and TST $(F(1.97)=5.81, p<0.01)$, with $11 \%$ of the variance in completion times accounted for by the model. However, TST did not mediate the relationship between $\mathrm{AH}$ severity and cognitive performance. Further mediation analyses using age as a covariate revealed no significant differences to outcomes (see Appendix A).

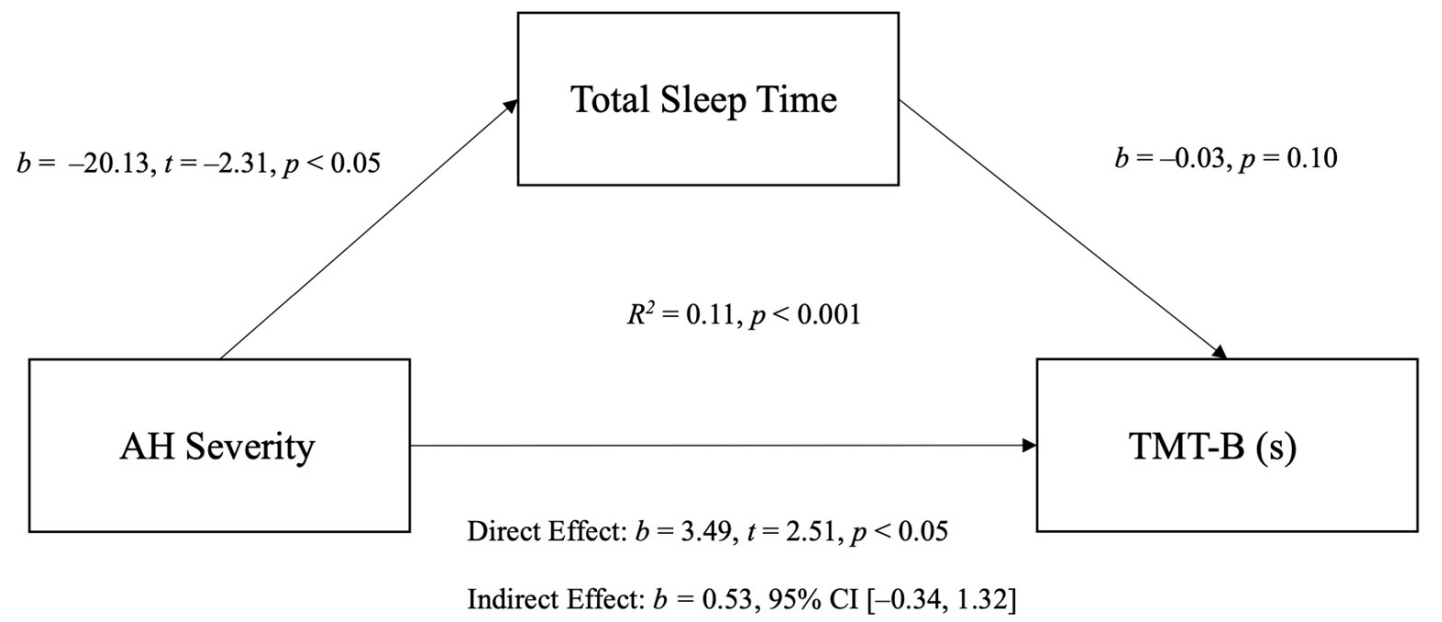

Figure 1. Mediation model for the relationship between AH severity, TMT-B (secs) and total sleep time.

\section{Discussion}

The current study explored the relationship between AH severity, sleep characteristics and cognitive performance using a naturalistic study design. Participants were recruited on their way home from an evening of drinking and completed $\mathrm{AH}$ and sleep measures as well as the TMT-B. The findings reveal that six out of the eight sleep characteristics correlated with at least one AH symptom. Duration of nightly awakenings correlated with the most AH symptoms. Total AH severity correlated with four sleep measures as well as TMT-B completion times. Several AH symptoms, as well as total sleep time (TST), also correlated with completion times on the TMT-B (s). However, TST did not mediate the relationship between AH severity and TMT-B (s) performance.

Firstly, our findings confirm that a night of drinking resulted in poorer subjective sleep quality compared with a normal night's sleep. This is in line with the majority of previous studies $[4,7,10,29]$, but not all $[12,25]$. In relation to individual AH symptoms, the duration of nightly awakenings correlated with the most $\mathrm{AH}$ symptoms, that is, six individual symptoms (clumsiness, thirst, sweating, shivering, nausea and heart pounding) and total AH severity. The number of awakenings also correlated with three individual symptoms (sweating, shivering and heart pounding) and total AH severity. Nightly awakenings are not commonly assessed in AH research, although Rohsenow et al. [10] similarly found that a longer duration of nightly awakenings resulted in higher AH severity using polysomnography. Likewise, a semi-naturalistic study found an increase in the number of nightly awakenings after consuming alcohol [4]. These findings highlight that experiencing nightly awakenings has a significant influence on $\mathrm{AH}$ symptom severity and should be included in future research. 
Other sleep characteristics that correlated with multiple AH symptoms were TST and sleep quality. Less TST and poorer sleep quality commonly resulted in higher ratings of fatigue and overall $\mathrm{AH}$ severity. These findings are similar to previous correlational research $[7,33,34]$ and somewhat reflect other semi-naturalistic studies that found a withinsubject reduction in TST [29] and/or poorer sleep quality during AH compared with non-AH conditions [28]. However, they differ from some experimental studies where non-significant differences in TST have been observed [10,25]. This could be due to the influence of experimental research on sleep hygiene. As such, in experimental research, bedtimes are generally scheduled and significantly earlier (before 12 a.m.) than those found in the current study (after 3 a.m.). The time allocated to sleep in these experimental studies is also adequate $(7-8 \mathrm{~h})$, sometimes with distractions, such as mobile phones, not allowed [10]. These factors promote good sleep hygiene and could unintentionally improve TST regardless of alcohol consumed. On the other hand, some of these studies had the advantage of measuring sleep objectively rather than relying on self-reported sleep. Considering self-report measures are prone to recall bias, this could alternatively explain the conflicting findings [28].

The findings for TMT-B performance reveal completion times to be related to seven individual $\mathrm{AH}$ symptoms, total $\mathrm{AH}$ severity and three characteristics of sleep. Total AH severity also accounted for a moderate but significant amount of variance in TMT-B completion times. Together, these findings were not unexpected given recent $\mathrm{AH}$ studies have reported within-subject effects of $\mathrm{AH}$ on various executive functions [9,39], with sleep disruptions also showing a similar relationship to cognitive impairment [40]. Despite this, when TST was included as a potential mediating variable, no mediation was observed in a model with overall AH severity. This provided no evidence that the association between $\mathrm{AH}$ severity and cognitive performance is mediated by sleep disturbances. This is similar to a previous study even though different sleep variables (sleep efficiency and REM \%) and cognitive measures were used (i.e., the psychomotor vigilance task and a continuous performance test) [10].

The reasons for a lack of mediation are not clear. Considering several other $\mathrm{AH}$ variables including "fatigue" also correlated with TMT-B (s), and these variables make up the average $\mathrm{AH}$ score, there is already some overlap in these constructs [10]. In addition, as various physiological mechanisms contribute to the range of $\mathrm{AH}$ symptoms, it may be the combination of these complex connections to $\mathrm{AH}$ impairment that has a greater impact over sleep loss alone. As an example, dehydration is a mechanism of AH that is related to poor concentration due to alcohol-induced changes in the anti-diuretic hormone vasopressin $[16,17,62]$. An alcohol-related immune response has also been associated with impaired memory performance due to the actions of increased concentrations of pro-inflammatory cytokines $[18,63]$. This, combined with poor sleep, may be one of the factors that contributes to poorer cognitive performance and that as assessed by the TMT-B.

The remaining sleep variables had little to no relationship with drinking, $\mathrm{AH}$ and cognitive performance. Although time to bed, time of final wake up and total time in bed correlated with few AH symptoms and/or TMT-B errors, these correlations were no higher than $r_{s}=0.21$ (except for time in bed and "fatigue", where $r_{s}=0.24$ ), meaning the relevance of these findings is questionable. Drinking characteristics also correlated with few variables. The hours of drinking and total amount of drinks consumed delayed time to bed, suggesting that a night out drinking occurs at the expense of sleep [26]. Similarly, the hours of drinking also reduced the total sleep time and total time in bed. However, BrAC was not related to any measure. This might be considered unusual as higher concentrations of alcohol can have a more pronounced effect on sleep architecture [21]. However, BrAC was also only taken when participants were on their way home and may not reflect the peak $\mathrm{BrAC}$ obtained. Other research has also suggested that subjective intoxication is a more important contributor to $\mathrm{AH}$ severity over $\mathrm{BrAC}$, so this may also explain some of the lack of findings here [64]. 
Regarding other findings, the single item "fatigue" was the only AH symptom related to TMT-B errors. It is difficult to draw any strong conclusions here considering $53 \%$ of the sample made no errors on the TMT-B and a further $25 \%$ made only one or two errors [34]. We have previously suggested that the impairment in speed on the TMT-B and relatively few errors may signify a differing effect of AH on the speed-accuracy trade-off (SATO) compared with that of acute intoxication [32]. This is due to several acute intoxication studies finding a characteristic shift in SATO with higher errors compared to relatively limited effects on response speed [65-67].

The findings in this study support growing evidence that $\mathrm{AH}$ is associated with poor sleep and cognitive performance. Adopting a naturalistic study design allowed for a unique perspective on drinking, $\mathrm{AH}$ and sleep. Although the mean scores on individual $\mathrm{AH}$ items were mostly low to moderate in severity (barring the single-items 'fatigue' and 'thirst'), these scores are highly consistent with previous research [68], including studies that reported a significant difference in symptom severity from control conditions and other correlational research assessing AH and sleep [33,34]. The BrAC readings obtained also reflect previous research, which suggests that sample selection was not biased and was representative of end-of-night intoxication [53,54]. However, a significantly later time to bed and lower TST were found compared with other studies. This could be considered a study strength, as it highlights the potential limitations of other research designs to obtain ecologically valid sleeping behavior after drinking. Another study strength was the cross-section of ages recruited. As previous research typically focussed on younger age groups, the current research emphasises that $\mathrm{AH}$ is not just experienced by younger drinkers. In addition, including age as a potential covariate in the mediation model did not change the outcomes.

This study was not without limitations. Firstly, participants were not screened for dependency issues, concurrent use of other psychoactive substances and sensitivity to AH. These factors have been causes for exclusion in previous research and have the potential to bias the results obtained in this study [26,69]. Secondly, although participants were on their way home for the evening, BrAC may not be reflective of the peak BrAC obtained, especially if participants consumed more alcohol once at home or had only recently finished drinking. Moreover, $\mathrm{BrAC}$ the following morning was not assessed, meaning the presence of $\mathrm{AH}$ (classified as $<0.02 \% \mathrm{BrAC}$ [8]) could not be confirmed.

Thirdly, this study was conducted in only one major location, which may limit generalisability to other cultures and societies. Limited generalisability could also be extended to the use of only one short cognitive task. Whilst the TMT-B has been shown to be a valid and reliable measure of executive functioning, it is difficult to generalise the negative effect of AH severity observed here to impairments in cognitive performance more broadly [42].

Further limitations of this research relate to overall $\mathrm{AH}$ severity. Recent research has indicated that a single-factor overall $\mathrm{AH}$ severity score may be a more reliable indicator of true $\mathrm{AH}$ severity over the average of individual $\mathrm{AH}$ items [70]. This is due to $\mathrm{AH}$ questionnaires not representing all possible $\mathrm{AH}$ symptoms, as well as variability in the presence and severity of common versus less frequent $\mathrm{AH}$ symptoms in the scale. As suggested previously, there was already potential overlap in the mediation model using the averaged overall AH severity, which includes the single-item score for "fatigue". Therefore, including a single-factor score may be more appropriate for any future research considering mediation.

Consistent with past AH research, the reliance on self-report measures which can be prone to bias is another limitation of the current study. This increased risk of bias also includes not restricting participants from knowing their BrAC results (i.e., potentially increasing the risk of expectancy effects the next morning) and asking participants about a normal night's sleep on the morning when experiencing AH. The use of objective sleep measures such as those used by Devenney et al. [28] was not possible for this type of research design but would add valuable insight into research on $\mathrm{AH}$ and sleep in the future, as would the use of experimental and within-subject research designs. As previous studies 
have also highlighted sex differences in sleep characteristics following alcohol [12,33,71], and an influence of beverage congeners on $\mathrm{AH}$ severity, this may be considered a possible limitation that could also be explored in future research.

\section{Conclusions}

Using a naturalistic study design, this study confirmed a relationship between $\mathrm{AH}$ symptom severity and several sleep characteristics. An exploration of the correlational relationship revealed the duration of nightly awakenings as the sleep variable that related to the most $\mathrm{AH}$ symptoms. This suggests waking after sleep onset should be consistently included in future AH research. AH severity also accounted for variance in a task of executive functioning, which has potential implications for complex task performance (such as driving) with an AH. However, TST was not a mediating influence on the relationship between AH severity and performance. Given this lack of mediation, future research could explore how other mechanistic variables such cytokine concentrations and dehydration may contribute alongside sleep to the complex relationship between $\mathrm{AH}$ severity and cognitive functioning. Future research should also consider the use of advanced technologies to obtain objective measures of sleep as well as within-subject methodologies to strengthen the above findings.

Author Contributions: Conceptualization, E.A., A.S., G.J.D., S.B.; methodology, E.A., A.S., D.W., G.J.D., J.C.V., S.B.; formal analysis, E.A., A.S., D.W., S.B.; investigation, G.J.D., S.B.; resources, C.A.; data curation, E.A., A.S., S.B.; writing —original draft preparation, E.A.; writing-reviewing and editing, A.S., D.W., G.J.D., J.K., J.C.V., S.B.; supervision, A.S., D.W., S.B.; project administration, G.J.D.; funding, G.J.D. All authors have read and agreed to the published version of the manuscript.

Funding: These data were drawn from a sample of a larger study funded by a grant to G.J.D. and C.A. from the National Drug Strategy Law Enforcement Funding Committee (\#1314004). The funders had no role in the design of the study (in the collection, analyses or interpretation of data), in the writing of the manuscript or in the decision to publish the results.

Institutional Review Board Statement: This study was conducted according to the guidelines of the Declaration of Helsinki and approved by Griffith University (2015/704) on 13 October 2015 and Swinburne University Human Research Ethics Committees (SUHREC, 2016/167) on 22 June 2016.

Informed Consent Statement: Informed consent was obtained from all subjects involved in the study.

Data Availability Statement: The data presented in this study are available on request from the corresponding author.

Acknowledgments: E.A. is a recipient of a Swinburne University Postgraduate Research Award.

Conflicts of Interest: S.B. has received funding from Red Bull GmbH, Kemin Foods, Sanofi Aventis, Phoenix Pharmaceutical, GlaxoSmithKline and BioRevive. A.S. has held research grants from Abbott Nutrition, Arla Foods, Bayer, BioRevive, DuPont, Fonterra, Kemin Foods, Nestlé, Nutricia-Danone and Verdure Sciences. He has acted as a consultant/expert advisor to Bayer, Danone, Naturex, Nestlé, Pfizer, Sanofi and Sen-Jam Pharmaceutical, and has received travel/hospitality/speaker fees from Bayer, Sanofi and Verdure Sciences. He is on the Scientific Advisory Board of Sen-Jam Pharmaceutical. Over the past 36 months, J.C.V. has acted as a consultant/expert advisor to KNMP, More Labs, Red Bull, Sen-Jam Pharmaceutical, Toast!, Tomo and ZBiotics. D.W. has received research funding from Abbott Nutrition, Arla Foods, Bayer Healthcare and Fonterra, and consultancy/speaker honoraria from Neurobrands, Naturex and Bayer Healthcare. G.J.D. and C.A. have received no funding from local or state governments, political organisations, lobby groups, registered health charities that promote temperance or companies involved in the supply or sale of alcohol.

\section{Appendix A}

The relationship between AH severity, TMT-B (s) and total sleep time, with age as a covariate. 
Observations of Mahalanobis's distance revealed two outlying cases when considering age as a potential covariate in the mediation model. Removal of these outliers did not change the significance of any relationship, and thus these were retained in the analysis. Figure A1 presents the mediation model for the relationship between AH severity, TMT-B (s) and total sleep time with age as a covariate. The overall model was significant $(F(1.96)=6.42, p<0.01)$, with $12 \%$ of the variance in TMT-B completion times accounted for by AH severity. With age as a covariate, the relationship between total sleep time and TMT-B (secs) was trending towards significance. However, total sleep time still did not mediate the relationship between $\mathrm{AH}$ severity and performance.

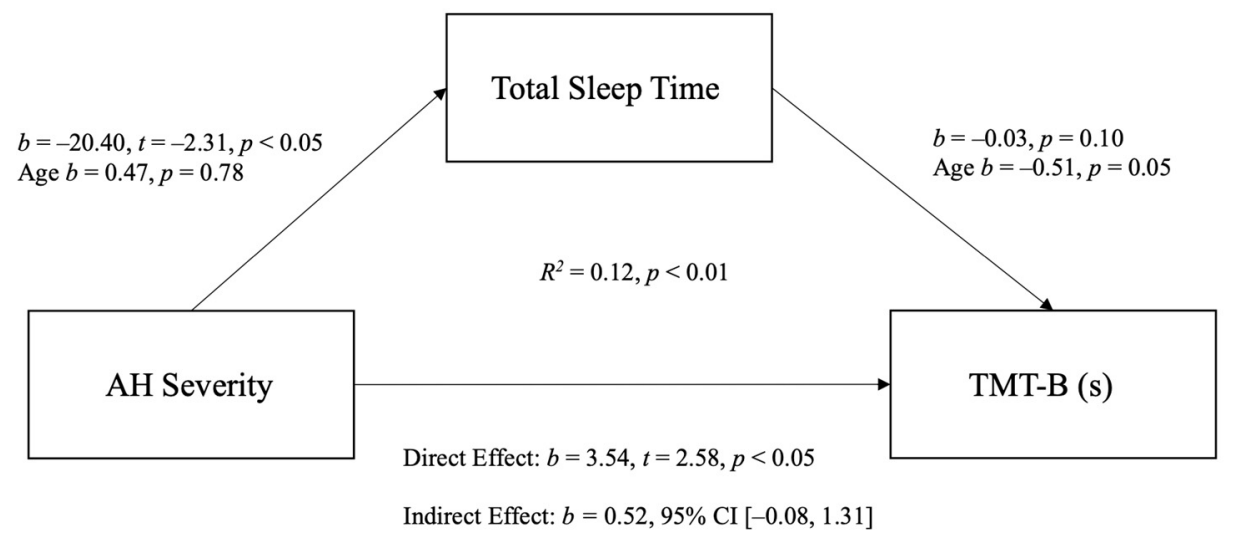

Figure A1. Mediation model for the relationship between AH severity, total sleep time and TMT-B completion times, with age as a covariate.

\section{References}

1. Verster, J.C.; Scholey, A.; van de Loo, A.J.A.E.; Benson, S.; Stock, A.-K. Updating the Definition of the Alcohol Hangover. J. Clin. Med. 2020, 9, 823. [CrossRef] [PubMed]

2. Van Schrojenstein Lantman, M.; van de Loo, A.J.A.E.; Mackus, M.; Verster, J.C. Development of a Definition for the Alcohol Hangover: Consumer Descriptions and Expert Consensus. Curr. Drug Abus. Rev. 2017, 9, 148-154. [CrossRef] [PubMed]

3. Verster, J.C.; Kruisselbrink, L.D.; Slot, K.A.; Anogeianaki, A.; Adams, S.; Alford, C.; Arnoldy, L.; Ayre, E.; Balikji, S.; Benson, S.; et al. Sensitivity to Experiencing Alcohol Hangovers: Reconsideration of the $0.11 \%$ Blood Alcohol Concentration (BAC) Threshold for Having a Hangover. J. Clin. Med. 2020, 9, 179. [CrossRef] [PubMed]

4. Benson, S.; Ayre, E.; Garrisson, H.; Wetherell, M.A.; Verster, J.C.; Scholey, A. Alcohol Hangover and Multitasking: Effects on Mood, Cognitive Performance, Stress Reactivity, and Perceived Effort. J. Clin. Med. 2020, 9, 1154. [CrossRef] [PubMed]

5. Penning, R.; McKinney, A.; Verster, J.C. Alcohol Hangover Symptoms and Their Contribution to the Overall Hangover Severity. Alcohol Alcohol. 2012, 47, 248-252. [CrossRef] [PubMed]

6. Slutske, W.S.; Piasecki, T.M.; Hunt-Carter, E.E. Development and Initial Validation of the Hangover Symptoms Scale: Prevalence and Correlates of Hangover Symptoms in College Students. Alcohol. Clin. Exp. Res. 2003, 27, 1442-1450. [CrossRef] [PubMed]

7. Verster, J.C.; Bervoets, A.C.; De Klerk, S.; Vreman, R.A.; Olivier, B.; Roth, T.; Brookhuis, K.A. Effects of alcohol hangover on simulated highway driving performance. Psychopharmacology 2014, 231, 2999-3008. [CrossRef] [PubMed]

8. Gunn, C.; Mackus, M.; Griffin, C.; Munafò, M.R.; Adams, S. A systematic review of the next-day effects of heavy alcohol consumption on cognitive performance. Addiction 2018, 113, 2182-2193. [CrossRef] [PubMed]

9. Gunn, C.; Fairchild, G.; Verster, J.C.; Adams, S. The Effects of Alcohol Hangover on Executive Functions. J. Clin. Med. 2020, 9, 1148. [CrossRef]

10. Rohsenow, D.J.; Howland, J.; Arnedt, J.T.; Almeida, A.B.; Greece, J.; Minsky, S.; Kempler, C.S.; Sales, S. Intoxication with bourbon versus vodka: Effects on hangover, sleep, and next-day neurocognitive performance in young adults. Alcohol. Clin. Exp. Res. 2010, 34, 509-518. [CrossRef] [PubMed]

11. Grange, J.A.; Stephens, R.; Jones, K.; Owen, L. The effect of alcohol hangover on choice response time. J. Psychopharmacol. 2016, 30, 654-661. [CrossRef] [PubMed]

12. Verster, J.C.; Van Duin, D.; Volkerts, E.R.; Schreuder, A.H.C.M.L.; Verbaten, M.N. Alcohol Hangover Effects on Memory Functioning and Vigilance Performance after an Evening of Binge Drinking. Neuropsychopharmacology 2002, 28, 740-746. [CrossRef]

13. McKinney, A.; Coyle, K.; Penning, R.; Verster, J.C. Next day effects of naturalistic alcohol consumption on tasks of attention. Hum. Psychopharmacol. Clin. Exp. 2012, 27, 587-594. [CrossRef] [PubMed]

14. Bhattacharya, A. Financial Headache: The Cost of Workplace Hangover and Intoxication to the UK Economy; Institute for Alcohol Studies: London, UK, 2019. 
15. Sacks, J.J.; Gonzales, K.R.; Bouchery, E.E.; Tomedi, L.E.; Brewer, R.D. 2010 National and State Costs of Excessive Alcohol Consumption. Am. J. Prev. Med. 2015, 49, e73-e79. [CrossRef] [PubMed]

16. Penning, R.; Van Nuland, M.; Fliervoet, L.A.; Olivier, B.; Verster, J.C. The Pathology of Alcohol Hangover. Curr. Drug Abus. Rev. 2010, 3, 68-75. [CrossRef] [PubMed]

17. Tipple, C.T.; Benson, S.; Scholey, A. A Review of the Physiological Factors Associated with Alcohol Hangover. Curr. Drug Abus. Rev. 2017, 9, 93-98. [CrossRef]

18. Van de Loo, A.J.A.E.; Mackus, M.; Kwon, O.; Krishnakumar, I.M.; Garssen, J.; Kraneveld, A.D.; Scholey, A.; Verster, J.C. The Inflammatory Response to Alcohol Consumption and Its Role in the Pathology of Alcohol Hangover. J. Clin. Med. 2020, 9, 2081. [CrossRef] [PubMed]

19. Rohsenow, D.J.; Howland, J. The role of beverage congeners in hangover and other residual effects of alcohol in-toxication: A review. Curr. Drug Abus. Rev. 2010, 3, 76-79. [CrossRef] [PubMed]

20. Tolstrup, J.S.; Stephens, R.; Grønbaek, M. Does the Severity of Hangovers Decline with Age? Survey of the Incidence of Hangover in Different Age Groups. Alcohol. Clin. Exp. Res. 2013, 38, 466-470. [CrossRef] [PubMed]

21. Roehrs, T.; Roth, T. Sleep, sleepiness, and alcohol use. Alcohol Res. Health J. Natl. Inst. Alcohol Abuse Alcohol. 2001, 25, 101-109.

22. Roehrs, T.; Roth, T. Sleep, sleepiness, sleep disorders and alcohol use and abuse. Sleep Med. Rev. 2001, 5, 287-297. [CrossRef] [PubMed]

23. Roehrs, T.; Yoon, J.; Roth, T. Nocturnal and next-day effects of ethanol and basal level of sleepiness. Hum. Psychopharmacol. Clin. Exp. 1991, 6, 307-311. [CrossRef]

24. Verster, J.C.; van de Loo, A.J.A.E.; Adams, S.; Stock, A.-K.; Benson, S.; Scholey, A.; Alford, C.; Bruce, G. Advantages and Limitations of Naturalistic Study Designs and Their Implementation in Alcohol Hangover Research. J. Clin. Med. 2019, 8, 2160. [CrossRef] [PubMed]

25. Rohsenow, D.J.; Howland, J.; Minsky, S.J.; Arnedt, J.T. Effects of Heavy Drinking by Maritime Academy Cadets on Hangover, Perceived Sleep, and Next-Day Ship Power Plant Operation. J. Stud. Alcohol 2006, 67, 406-415. [CrossRef]

26. Hogewoning, A.; van de Loo, A.; Mackus, M.; Raasveld, S.J.; De Zeeuw, R.; Bosma, E.R.; Bouwmeester, N.; Brookhuis, K.; Garssen, J.; Verster, J.C. Characteristics of social drinkers with and without a hangover after heavy alcohol consumption. Subst. Abus. Rehabil. 2016, 7, 161-167. [CrossRef] [PubMed]

27. Stephens, R.; Grange, J.A.; Jones, K.; Owen, L. A critical analysis of alcohol hangover research methodology for surveys or studies of effects on cognition. Psychopharmacology 2014, 231, 2223-2236. [CrossRef] [PubMed]

28. Devenney, L.E.; Coyle, K.B.; Roth, T.; Verster, J.C. Sleep after Heavy Alcohol Consumption and Physical Activity Levels during Alcohol Hangover. J. Clin. Med. 2019, 8, 752. [CrossRef]

29. McKinney, A.; Coyle, K. Alcohol hangover effects on measures of affect the morning after a normal night's drinking. Alcohol Alcohol. 2006, 41, 54-60. [CrossRef] [PubMed]

30. Finnigan, F.; Hammersley, R.; Cooper, T. An examination of next-day hangover effects after a $100 \mathrm{mg} / 100 \mathrm{~mL}$ dose of alcohol in heavy social drinkers. Addiction 1998, 93, 1829-1838. [CrossRef]

31. Stephens, R.; Ling, J.; Heffernan, T.M.; Heather, N.; Jones, K. A review of the literature on the cognitive effects of alcohol hangover. Alcohol Alcohol. 2008, 43, 163-170. [CrossRef]

32. Scholey, A.; Benson, S.; Kaufman, J.; Terpstra, C.; Ayre, E.; Verster, J.C.; Allen, C.; Devilly, G.J. Effects of Alcohol Hangover on Cognitive Performance: Findings from a Field/Internet Mixed Methodology Study. J. Clin. Med. 2019, 8, 440. [CrossRef] [PubMed]

33. Van Schrojenstein Lantman, M.; Mackus, M.; Roth, T.; Verster, J.C. Total sleep time, alcohol consumption, and the duration and severity of alcohol hangover. Nat. Sci. Sleep 2017, 9, 181-186. [CrossRef] [PubMed]

34. Van Schrojenstein Lantman, M.; Roth, T.; Roehrs, T.; Verster, J.C. Alcohol hangover, sleep quality, and daytime sleepiness. Sleep Vigil. 2017, 1, 37-41. [CrossRef]

35. Alford, C.; Martinkova, Z.; Tiplady, B.; Reece, R.; Verster, J.C. The effects of alcohol hangover on mood and performance assessed at home. J. Clin. Med. 2020, 9, 1068. [CrossRef] [PubMed]

36. McKinney, A.; Coyle, K. Next day effects of a normal night's drinking on memory and psychomotor performance. Alcohol Alcohol. 2004, 39, 509-513. [CrossRef] [PubMed]

37. McKinney, A.; Coyle, K. Next-day effects of alcohol and an additional stressor on memory and psychomotor performance. J. Stud. Alcohol Drugs 2007, 68, 446-454. [CrossRef]

38. Devenney, L.E.; Coyle, K.B.; Verster, J.C. Memory and attention during an alcohol hangover. Human Psychopharmacol. Clin. Exp. 2019, 34, e2701. [CrossRef]

39. Devenney, L.E.; Coyle, K.B.; Verster, J.C. Cognitive performance and mood after a normal night of drinking: A naturalistic alcohol hangover study in a non-student sample. Addict. Behav. Rep. 2019, 10, 100197. [CrossRef]

40. Lim, J.; Dinges, D.F. A meta-analysis of the impact of short-term sleep deprivation on cognitive variables. Psychol. Bull. 2010, 136, 375-389. [CrossRef]

41. Pilcher, J.J.; Huffcutt, A.I. Effects of Sleep Deprivation on Performance: A Meta-Analysis. Sleep 1996, 19, 318-326. [CrossRef]

42. Arbuthnott, K.; Frank, J. Trail Making Test, Part B as a Measure of Executive Control: Validation Using a Set-Switching Paradigm. J. Clin. Exp. Neuropsychol. 2000, 22, 518-528. [CrossRef]

43. Bowie, C.R.; Harvey, P.D. Administration and interpretation of the Trail Making Test. Nat. Protoc. 2006, 1, 2277-2281. [CrossRef] 
44. Titova, O.E.; Lindberg, E.; Elmståhl, S.; Lind, L.; Schiöth, H.B.; Benedict, C. Association between shift work history and performance on the trail making test in middle-aged and elderly humans: The EpiHealth study. Neurobiol. Aging 2016, 45, 23-29. [CrossRef]

45. Saint Martin, M.; Sforza, E.; Barthélémy, J.C.; Thomas-Anterion, C.; Roche, F. Does subjective sleep affect cognitive function in healthy elderly subjects? The Proof cohort. Sleep Med. 2012, 13, 1146-1152. [CrossRef]

46. Wimmer, F.; Hoffmann, R.F.; Bonato, R.A.; Moffitt, A.R. The effects of sleep deprivation on divergent thinking and attention processes. J. Sleep Res. 1992, 1, 223-230. [CrossRef]

47. Dry, M.J.; Burns, N.R.; Nettelbeck, T.; Farquharson, A.L.; White, J.M. Dose-Related Effects of Alcohol on Cognitive Functioning. PLOS ONE 2012, 7, e50977. [CrossRef]

48. Guillot, C.R.; Fanning, J.R.; Bullock, J.S.; McCloskey, M.S.; Berman, M.E. Effects of alcohol on tests of executive functioning in men and women: A dose response examination. Exp. Clin. Psychopharmacol. 2010, 18, 409-417. [CrossRef] [PubMed]

49. Gilbertson, R.; Prather, R.; Nixon, S. Acute alcohol administration and placebo effectiveness in older moderate drinkers: Influences on cognitive performance. J. Stud. Alcohol Drugs 2010, 71, 345-350. [CrossRef] [PubMed]

50. Howse, A.D.; Hassall, C.D.; Williams, C.C.; Hajcak, G.; Krigolson, O.E. Alcohol hangover impacts learning and reward processing within the medial-frontal cortex. Psychophysiology 2018, 55, e13081. [CrossRef]

51. Murgia, M.; Mingolo, S.; Prpic, V.; Sors, F.; Santoro, I.; Bilotta, E.; Agostini, T. University Students' Hangover May Affect Cognitive Research. Front. Psychol. 2020, 11, 573291. [CrossRef] [PubMed]

52. Devilly, G.J.; Allen, C.; Brown, K. SmartStart: Results of a large point of entry study into preloading alcohol and associated behaviours. Int. J. Drug Policy 2017, 43, 130-139. [CrossRef] [PubMed]

53. Devilly, G.J.; Greber, M.; Brown, K.; Allen, C. Drinking to go out or going out to drink? A longitudinal study of alcohol in night-time entertainment districts. Drug Alcohol Depend. 2019, 205, 107603. [CrossRef]

54. Devilly, G.J.; Hides, L.; Kavanagh, D.J. A big night out getting bigger: Alcohol consumption, arrests and crowd numbers, before and after legislative change. PLoS ONE 2019, 14, e0218161. [CrossRef]

55. Sorbello, J.G.; Devilly, G.J.; Allen, C.; Hughes, L.R.; Brown, K. Fuel-cell breathalyser use for field research on alcohol intoxication: An independent psychometric evaluation. PeerJ 2018, 6, e4418. [CrossRef] [PubMed]

56. Australian Government Department of Health. Standard Drinks Guide; Australian Government Department of Health: Canberra, Australia, 2020.

57. Penning, R.; McKinney, A.; Bus, L.D.; Olivier, B.; Slot, K.; Verster, J.C. Measurement of alcohol hangover severity: Development of the Alcohol Hangover Severity Scale (AHSS). Psychopharmacology 2012, 225, 803-810. [CrossRef]

58. Carney, C.E.; Buysse, D.J.; Ancoli-Israel, S.; Edinger, J.D.; Krystal, A.D.; Lichstein, K.L.; Morin, C.M. The consensus sleep diary: Standardizing prospective sleep self-monitoring. Sleep 2012, 35, 287-302. [CrossRef]

59. Devenney, L.E.C.; Coyle, K.B.; Verster, J.C. The impact of expectancy on cognitive performance during alcohol hangover. BMC Res. Notes 2018, 11, 730. [CrossRef]

60. Tabachnick, B.G.; Fidell, L.S.; Ullman, J.B. Using Multivariate Statistics; Pearson: Boston, MA, USA, 2007; Volume 5.

61. Preacher, K.J.; Hayes, A.F. SPSS and SAS procedures for estimating indirect effects in simple mediation models. Behav. Res. Methods Instrum. Comput. 2004, 36, 717-731. [CrossRef] [PubMed]

62. Palmer, E.; Tyacke, R.; Sastre, M.; Lingford-Hughes, A.; Nutt, D.; Ward, R.J. Alcohol hangover: Underlying biochemical, inflammatory and neurochemical mechanisms. Alcohol Alcohol. 2019, 54, 196-203. [CrossRef]

63. Kim, D.-J.; Kim, W.; Yoon, S.-J.; Choi, B.-M.; Kim, J.-S.; Go, H.J.; Kim, Y.-K.; Jeong, J. Effects of alcohol hangover on cytokine production in healthy subjects. Alcohol 2003, 31, 167-170. [CrossRef]

64. Verster, J.C.; Arnoldy, L.; van de Loo, A.J.A.E.; Benson, S.; Scholey, A.; Stock, A.-K. The Impact of Mood and Subjective Intoxication on Hangover Severity. J. Clin. Med. 2020, 9, 2462. [CrossRef]

65. Scholey, A.B.; Benson, S.; Neale, C.; Owen, L.; Tiplady, B. Neurocognitive and mood effects of alcohol in a naturalistic setting. Hum. Psychopharmacol. 2012, 27, 514-516. [CrossRef]

66. Tiplady, B.; Franklin, N.; Scholey, A. Effect of ethanol on judgements of performance. Br. J. Psychol. 2004, 95, 105-118. [CrossRef]

67. Benson, S.; Tiplady, B.; Scholey, A. Attentional and working memory performance following alcohol and energy drink: A randomised, double-blind, placebo-controlled, factorial design laboratory study. PLoS ONE 2019, 14, e0209239. [CrossRef]

68. Scholey, A.; Ayre, E.; Stock, A.-K.; Verster, J.C.; Benson, S. Effects of rapid recovery on alcohol hangover severity: A double-blind, placebo-controlled, factorial design laboratory study. J. Clin. Med. 2020, 9, 2175. [CrossRef]

69. Prat, G.; Adan, A.; Pérez-Pàmies, M.; Sànchez-Turet, M. Neurocognitive effects of alcohol hangover. Addict. Behav. 2008, 33, 15-23. [CrossRef]

70. Verster, J.C.; van de Loo, A.J.; Benson, S.; Scholey, A.; Stock, A.-K. The Assessment of Overall Hangover Severity. J. Clin. Med. 2020, 9, 786. [CrossRef]

71. Arnedt, J.T.; Rohsenow, D.J.; Almeida, A.B.; Hunt, S.K.; Gokhale, M.; Gottlieb, D.J.; Howland, J. Sleep Following Alcohol Intoxication in Healthy, Young Adults: Effects of Sex and Family History of Alcoholism. Alcohol. Clin. Exp. Res. 2011, 35, 870-878. [CrossRef] 